\title{
Regenerative response of different regions of Drosophila imaginal discs
}

\author{
RAQUEL MARTÍN and GINÉS MORATA* \\ Centro de Biología Molecular, CSIC-UAM, Madrid, Spain
}

\begin{abstract}
Thanks to the introduction of new methods to induce massive damage under controlled conditions, much information about regeneration in Drosophila imaginal discs has accumulated in recent years. In this review, we discuss results concerning primarily the wing disc, putting emphasis on the different regenerative responses of the wing appendage, which exhibits a robust regenerative potential, and the trunk region, the notum, which regenerates very poorly. The wing disc may be a paradigm of a tissue in which a common original lineage generates cells with distinct regenerative potential. We argue that a key factor in those differences is the activity of the Jun $\mathrm{N}$-terminal Kinase (JNK) pathway, which functions differently in the appendage and the body trunk.
\end{abstract}

KEY WORDS: Drosophila, imaginal disc, regeneration, $7 \mathcal{N K}$

\section{Introduction}

The term regeneration refers to the capacity of many organisms to reconstruct tissues or organs that have been damaged or amputated. It is a widespread feature of many animal groups (reviewed by Tanaka and Reddien 2011), although the regenerative potential varies greatly among animal species. Planarians for example, are able to regenerate most body parts from small fragments, whereas in vertebrates regeneration is generally more restricted, and mammals in particular show very limited regenerative response. Moreover, the regenerative response is not uniform in all body parts, even in highly regenerative vertebrates like salamanders or frogs some tissues are more regenerative than others; amputated limbs are fully regenerated, while regeneration is not complete after removal of internal organs. Why some organisms can regenerate and others do not, and why some tissues are more regenerative than others is a major unresolved problem in the field. The study of the regeneration potential of different tissues within the same organism may provide important insights into the problem.

In this review we will focus on the fruitfly Drosophila and will discuss recent findings regarding the regenerative potential of the imaginal discs and in particular the distinct regenerative capacity of different regions. The imaginal discs are sac-like structures that contain the precursors of the adult cuticle derivatives and are named after the adult structure they specify e.g. wing disc, leg disc, eye-antennal disc and so forth. Over the years the imaginal discs have been a model system to study a number of developmental processes at the cellular, genetic and molecular levels and as a result there is a wealth of information about their development. Most of the results we will be discussing in this review concern the wing disc, which forms not only the wing appendage but also the part of the body trunk corresponding to the second thoracic segment (Fig. 1A).

\section{Developmental features of the imaginal discs}

The imaginal discs are subdivided into areas of restricted lineage called compartments (García-Bellido et al., 1973). All the discs share the subdivision into Anterior $(A)$ and Posterior $(P)$ compartments. This is a very early lineage restriction, established during embryogenesis and that affects all body segments (Lawrence and Morata, 1977). A key genetic factor involved in the A/P subdivision is the activity of the gene engrailed (Morata and Lawrence, 1975), which determines the specific identity of the posterior cells.

In the wing disc there are two further lineage restrictions, one delimiting the Dorsal (D) and Ventral (V) compartments and another separating the trunk region (Notum, N) and the appendage (Wing plus Hinge, WH) regions (García-Bellido et al., 1973; Morata and Lawrence, 1979; Díaz-Benjumea and Cohen, 1993).

The notum forms the dorsal thoracic body wall of the adult fly and the $\mathrm{WH}$ includes the presumptive wing and the hinge. Both the D/V and the N/WH subdivisions occur during the larval period, approximately at the interphase of II and III larval stages (GarcíaBellido et al., 1973; Morata and Lawrence, 1979). The gene apterous

Abbreviations used in this paper: JNK, Jun N-terminal kinase; PNR, pannier; RN, rotund.

\footnotetext{
*Address correspondence to: Ginés Morata. Centro de Biología Molecular, CSIC-UAM, Madrid, Spain. E-mail: gmorata@cbm.csic.es (iD) http://orcid.org/0000-0003-3274-5173
} 
A
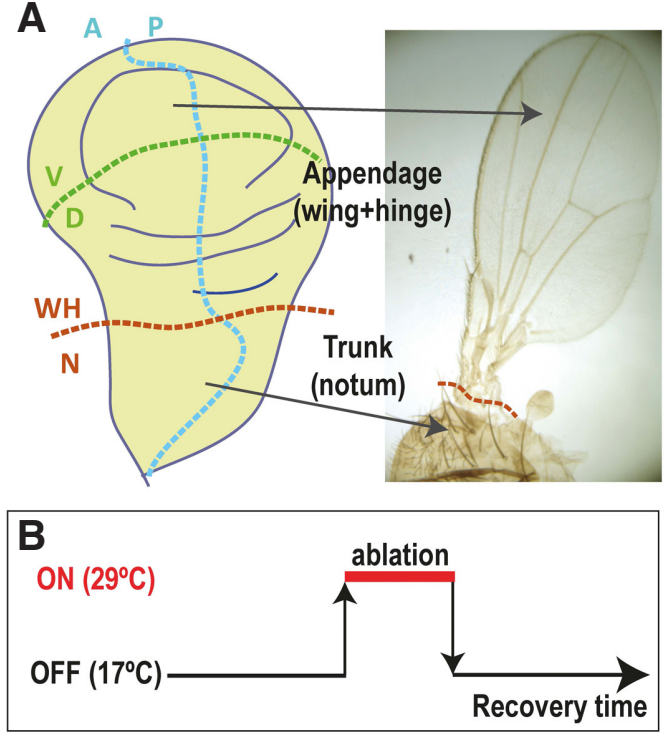

C $r n-G A L 4>U A S-r p r$
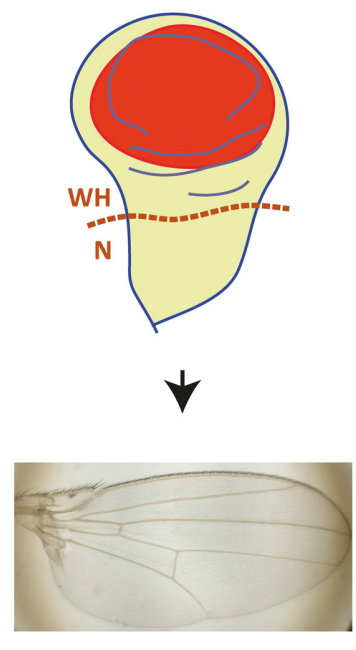

D
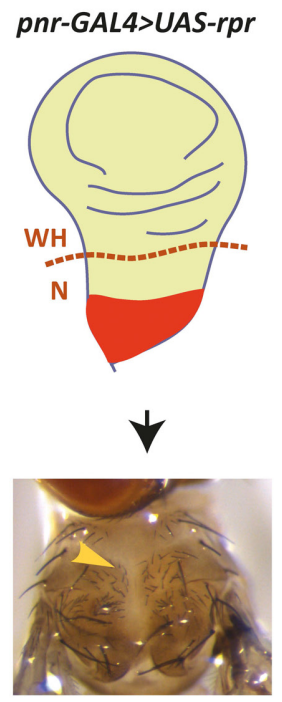

Fig. 1. Different regenerative response of wing and notum territories. (A) Subdivisions of a 3rd instar wing imaginal disc and the correspondent territories in the adult fly. The blue dashed line divides the disc into $A$ and $P$ compartments and the green dashed line separates $D$ and $V$ compartments. The notum is delimited from the wing/hinge by the brown dashed line in the wing disc and in the adult. (B) Scheme of the method of genetic ablation: larvae are grown at $17^{\circ} \mathrm{C}$ for a certain period of time and shifted to $29^{\circ} \mathrm{C}$ to induce ablation for the desired period of time. After the ablation period, they are returned to $17^{\circ} \mathrm{C}$ to allow regeneration and recovery. The system is modulated by the action of the thermo-sensitive GAL80 repressor. (C) The transient genetic ablation of the Rn domain (in red) triggers full regeneration of the wing tissue and results in the formation of an almost normal wing. (D) The genetic ablation of the Pnr territory (in red) within the notum does not induce regeneration and the adult flies lack the correspondent dorsal thorax territory (indicated with a yellow arrowhead).
(Díaz-Benjumea and Cohen, 1993) is instrumental in establishing the identity of the dorsal cells, and Vein/EGFR signalling activity makes notum cells distinct from and immiscible with wing-hinge cells (Zecca and Struhl, 2002). It is worth emphasizing that the belonging to a compartment reflects the expression of a specific genetic program that determines the development of a distinct body part. This program normally remains stable for the rest of the development, thus the transgression of a compartment boundary during regeneration would amount to a reprogramming process (see discussion in Morata and Herrera, 2016).

In addition to compartments, the imaginal discs include other regions that are not defined by cell lineage but by the expression of certain developmental genes like rotund $(r n)$ or pannier (pnr) (Fig. 1 C,D). The main difference with compartments is that they are open lineage domains and can incorporate cells from outside the domains until late in development.

\section{Experimental systems to study regeneration in imaginal discs}

\section{Transplantation experiments}

The imaginal discs have been subject of classical studies on regeneration. Those experiments (Nöthiger and Schubiger, 1966; Haynie and Bryant, 1976, reviewed in Worley et al., 2012) involved the transplantation of fragments of discs into adult female hosts and then studying how those fragments regenerate the missing parts. One important conclusion was that some disc fragments have a high regenerative potential, as they were often able to rebuild the whole structure. Interestingly, some fragments failed to regenerate the missing parts and formed instead duplication of their own patterns (Bryant, 1975), indicating a limited regenerative response.

Using this method, it was also found that most of cell proliferation occurs at the edge of the disc fragments (Dunne, 1981) and is associated with up regulated expression of the Jun $\mathrm{N}$-Terminal Kinase (JNK) signalling pathway (Bosch et al., 2005). This ectopic
JNK and subsidiary Dpp/Wg signalling has an important role in disc regeneration, and also in other organisms like Hydra (Chera et al., 2009). Furthermore, JNK up regulation facilitates changes in cell identity during regeneration, through down regulation of the Polycomb group of genes (Lee et al., 2005).

Transplantation experiments have been of significant importance in the field, as they provided interesting information about the regenerative potential of imaginal cells and have also identified genes and molecules relevant to the process. The main problem is that they are tedious and time consuming, and are sometimes hard to reproduce because the imprecision of cutting fragments manually under the dissecting microscope.

\section{Genetic ablation}

More recently, the development of genetic methods to induce ablation (Smith-Bolton et al., 2009) has allowed accurate reproducibility of the experiments and provides a convenient system to study the basis of regeneration in imaginal discs. Essentially, the method consists (Fig. 1B) of inducing massive damage in specific and well-delimited regions (as defined by Gal4 drivers) of the discs and following the regenerative response after the end of the ablation. Tools to induce damage are pro-apoptotic genes like reaper (rpr), hid or eiger (egr), known to be very effective in provoking cell death (Smith-Bolton et al., 2009; Bergantiños et al., 2010; Sun and Irvine, 2011; Herrera et al., 2013; Martín et al., 2017). It is of interest that some pro-apoptotic factors are more effective in cell killing than others, what allows studying regeneration after different levels of damage.

\section{Different regeneration potential of the appendage and trunk regions of the wing disc}

As mentioned above, the wing disc is subdivided into several compartments and genetic domains (Fig. 1A). A major compartmental distinction is between the appendage, which includes the 
hinge and the wing blade, and the trunk, which includes the dorsal thoracic part of the body wall, the notum.

A number of published experiments have described the regenerative potential of the different appendage regions (Smith-Bolton et al., 2009; Bergantiños et al., 2010; Herrera et al., 2013, Herrera and Morata, 2014). The experiments consisted of inducing massive damage in specific regions of the appendage by forcing in them high levels of apoptotic activity. In some cases, like the Rotund (Rn) domain (Fig. 1C), the ablated area is an open lineage domain, whereas in others, like the $\mathrm{P}$ or the $\mathrm{D}$ compartment, the ablated regions are lineage-restricted. The results, reported by several groups, have established that the appendage regions possess a remarkable capacity to regenerate. In the case of $\mathrm{Rn}$, the elimination of the majority of the cells (Smith-Bolton et al., 2009; Herrera et al., 2013) induces a proliferative response in regions outside the domain (and presumably in the surviving cells within the domain) followed by repopulation of the damaged domain by cells originated outside. It is of interest that this is a very quick and dynamic response that is initiated concomitant with the beginning of the ablation (Herrera et al., 2013).

Another clear demonstration of the regeneration capability of the appendage cells stands from experiments in which the sd-Gal4 line forces the expression of the pro-apoptotic gene hid in all the appendage cells. hid is an effective cell killer but does not eliminate all the cells; lineage tracing experiments show that the few wing appendage cells that survive the treatment are able to reconstruct the entire structure (Martín et al., 2017).

A pertinent question was if the strong regenerative potential of the appendage would include transgressions of compartment boundaries during the process. As pointed out above, the change of compartment identity would amount to a major genetic reprogramming. This possibility was assayed in experiments in which either the posterior or the dorsal compartment was ablated (Herrera and Morata, 2014), and subsequently the damaged disc was allowed to recover after the ablation. The clear result from these experiments was that after ablation both the A/P and D/V compartment boundaries collapse transiently and are quickly re-established. During the collapse, cells from anterior and posterior provenance can freely mix, and as a result cells from the original anterior or posterior compartment may acquire the alternative posterior or anterior identity when the compartment border is restored. This phenomenon was hinted in a classical regeneration experiment by Szabad et al., 1979. The changes in identity between anterior and posterior are associated with changes in the activity of the identity gene engrailed (en) (Herrera and Morata, 2014). It is noteworthy that anterior and posterior identities are established in early embryogenesis as a consequence of the activation of en in the posterior compartments (see general discussion in Lawrence, 1992). Therefore the acquisition of en expression de novo during the larval period requires a special activation event. One possibility, mentioned in more detail is a recent review (Morata and Herrera, 2016), is that it may be achieved by a mechanism akin to the "Community effect" (Gurdon, 1988). This mechanism proposes that "naïve" cells interact with neighbour cells and acquire new identity under the influence of the neighbours.

Thus, the general result is that the wing appendage shows a very strong regeneration potential: even after the elimination of the majority of the appendage the surviving cells can reconstruct the entire structure, and during the process they can undergo major reprogramming events. Within the appendage, recent work (Verghese and Su, 2016) has identified a subset of cells in the wing hinge that show resistance to IR-induced apoptosis and behave as a stem cell population. Lineage tracing experiments showed that those cells contribute to the repopulation of the wing pouch region. This results indicates a special regenerative ability of the cells at

\section{pnr-GAL4>UAS-rpr}
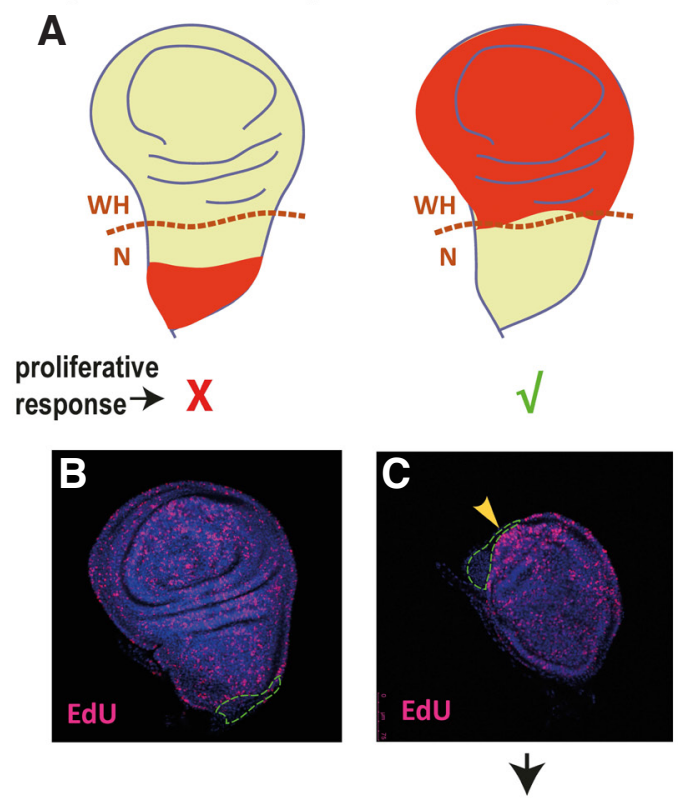

(A) The ablation of the Pnr domain (in red) does not elicit a significant proliferative response in the wing disc, in contrast to the ablation of the Sd and 41D11 domains (also in red), which results in increased cell proliferation, as indicated by EdU staining. (B-D). EdU staining is uniform in a pnr>rpr ablated disc (B), whereas it is more intense in the region close to the ablated area (green dashed line) in an $\mathrm{sd}>\mathrm{rpr}$ disc (C) and in a large region of a 41D11>rpr ablated disc (D). (E) The over-proliferation of cells in an sd>rpr disc results in the duplication of the Wg stripe characteristic of the notum (yellow arrowheads) and eventually in the formation of an ectopic notum ( $n^{\prime}$ ) instead of a wing in the adult fly (G). (F) The over-proliferation of cells in a 41D11>rpr disc results in a large overgrowth (delimited by the white dashed line), although the notum (labelled by Eyg and indicated by the white bracket) does not regenerate and remains residual.
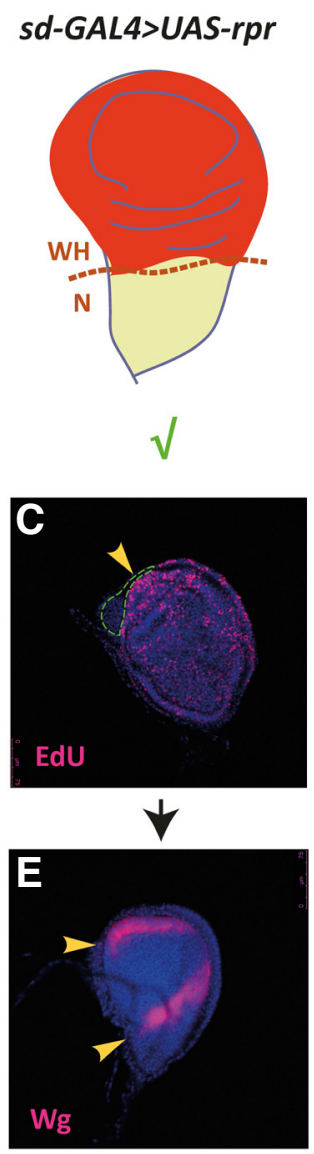

41D11-GAL4>UAS-rpr
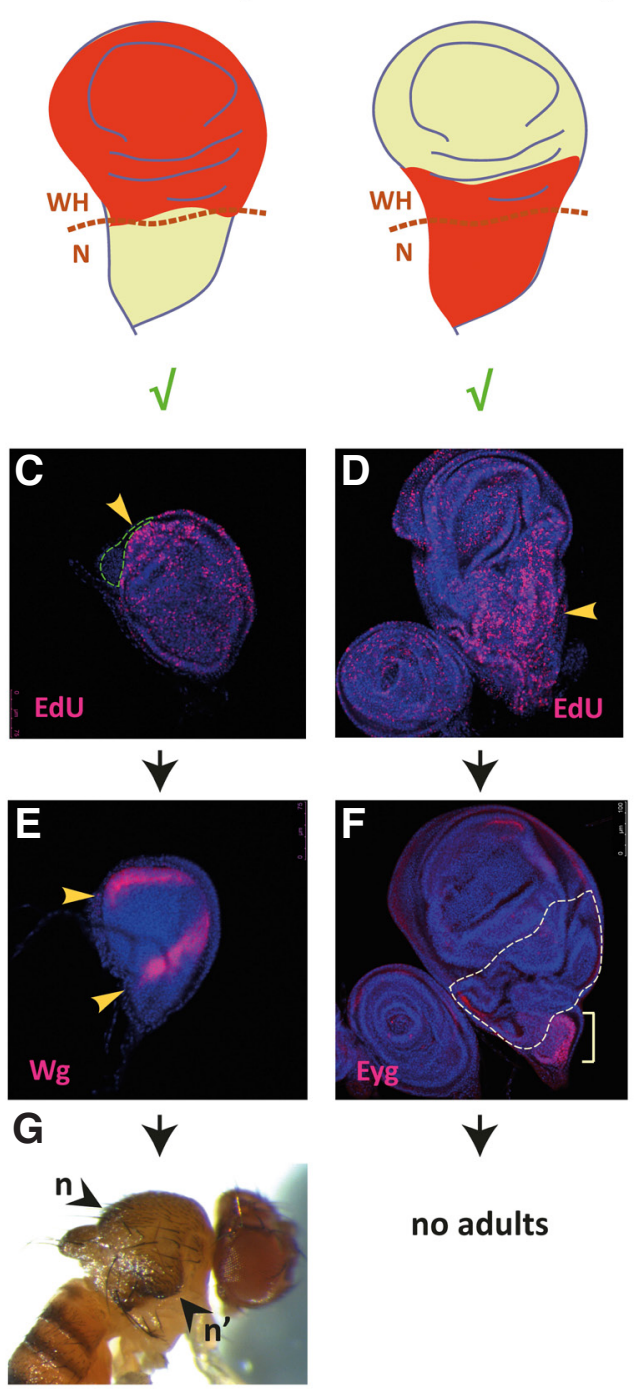

no adults 
the hinge, although surviving cells of the pouch also contribute to the regeneration (Smith-Bolton et al., 2009; Herrera et al., 2013).

In contrast with the appendage, the notum appears to have little, if any, regenerative potential. We have recently examined the response of notum cells to the elimination of different regions of the notum territory and found that these cells are not capable of repairing a damaged region. The lack of regenerative response to the elimination of Pnr domain can be readily visualised in surviving adult flies, which lack the corresponding cuticle structures (Fig. 1D). Furthermore, the absence of regeneration within the notum correlates with a lack of proliferative response to the ablation (Fig. $2 \mathrm{~A}, \mathrm{~B})$. That result is novel and intriguing as it indicates that in spite of their common lineage, different regions of the disc show different regenerative potential.

The lack of regeneration of notum regions opened the question of whether notum cells are able to send and/or to respond to proliferative signals after tissue damage. The finding that massive cell death on the wing region induces additional proliferation of notum cells (Martín et al., 2017) clearly demonstrates that these cells can respond to proliferative signals, at least when originated in the wing cells (see below).

\section{During regeneration, trunk and appendage structures cannot be reprogrammed to regenerate each other}

A recent finding (Martín et al., 2017) is that notum cells can undergo additional proliferation triggered by signals emanating from dying wing cells, but are unable to regenerate wing structures; they only form notum patterns (Fig. 2 A,C,E,G). Conversely, the elimination of most of the notum cells provokes a strong proliferative reaction of the appendage cells, which results in overgrowing hinge structures, but they fail to regenerate a notum (Fig. 2 $A, D, F)$. Thus, although the appendage cells have a remarkable capacity to regenerate appendage structures, they appear not to have the potential to regenerate a notum.

These observations point out the existence of a strict developmental restriction between trunk and appendage structures in the wing disc; once they have acquired their specific notum or wing/hinge identity, the cells cannot adopt the alternative developmental program, even after strong proliferative stimuli. This is in sharp contrast with the plasticity of the $A$ and $P$ compartments cells, which can alter their identity in response to massive tissue damage (Herrera and Morata, 2014). It is of interest that the A/P compartment subdivision occurs during embryogenesis (Morata and Lawrence, 1975) and is much earlier than the N/WH one, which is established roughly at the middle of the larval period (Morata and Lawrence, 1979). Yet the segregation into body trunk and appendage is more resilient than the subdivision into A/P compartments. At present we do not know the reason(s) for this difference.

\section{Roles of the JNK pathway in regeneration processes}

The Jun $\mathrm{N}$-terminal Kinase (JNK) signalling is a stress-response transduction pathway, also involved in many distinct processes: cell migration during embryonic dorsal closure and thorax closure, cell proliferation, tissue repair, etc. JNK signalling is up regulated during tissue-damage and is known to control multiple aspects of regeneration in Drosophila and other organisms (Behrens et al., 2002; Tasaki et al., 2011, Almuedo-Castillo et al., 2014). The implication of JNK in imaginal disc regeneration was first described during wound healing in regenerating imaginal discs. Its function is required at the edges of the wound area during the process of connecting the epithelial edges of the wound (Bosch et al., 2005).

One important problem concerns the mechanism of initial JNK activation after a stress event. Oxidative stress has been reported to be a primary signal during regeneration in planarians (Pirotte et al., 2015) and vertebrates (Love et al., 2013; Niethammer et al., 2009). In flies, recent work has demonstrated that the production of Reactive Oxigen Species (ROS) by damaged cells is a triggering factor for JNK activation during tissue damage and regeneration (Santabárbara et al., 2015; Brock et al., 2017). Furthermore, to ensure re-growth, JNK activity appears to be sustained for several days after damage by a mechanism involving ROS (Khan et al., 2017).

A relevant feature of $\mathrm{JNK}$ signalling is that it mediates the release of mitogenic signals by dying cells (Ryoo et al., 2004; Pérez-Garijo et al., 2004; 2009, reviewed in Fuchs and Steller, 2011; King and Newmark, 2012; Vriz et al., 2014). One of these mitogenic signals is the protein $\mathrm{Wg}$, which has been reported to play an important role during regeneration of the wing disc (Smith-Bolton et al., 2009). Moreover, the decreased regenerative capacity of mature wing discs correlates with a strong reduction in Wg up-regulation (Harris et al., 2016). Wg signalling is also essential for regenerative responses in other organisms like planarians, hydra and vertebrates (Gurley et al., 2008; Petersen and Reddien, 2008; Lengfeld et al., 2009; Chera et al., 2009; Kawakami et al., 2006; Stoick-Cooper et al., 2007; Yokoyama et al., 2007; Lin and Slack, 2008). The mitogenic signals released by apoptotic cells appear to be critical for the activation of the proliferative response in some regeneration processes. JNK is also required for the local cell proliferation elicited after the ablation of the patch domain in the wing disc (Bergantiños et al., 2010). Moreover, inhibition of JNK signalling in dying wing cells after massive apoptosis prevents the over-proliferation of notum cells and the formation of duplicated nota (Martín et al., 2017).

JNK is also involved in other aspects of regeneration in imaginal discs, for example, it appears to be necessary for the migration of cells towards the damaged area during the re-construction of an ablated Rotund domain in the wing disc (Herrera et al., 2013). A very significant role of JNK is its implication in re-patterning of the regenerating tissue, which involves genetic reprogramming of the cells implicated in the process. In normal circumstances the identity of the imaginal cells, once established, remains stable through the epigenetic control exerted by the Polycomb (PcG) and trithorax ( $\operatorname{tr} \mathrm{G}$ ) groups of genes. In regenerating tissue there is evidence of down regulation of the $\mathrm{PcG}$, a process mediated by the up regulation of the JNK (Lee et al., 2005). The modification of the PcG function may allow the reprogramming of regenerating cells. Furthermore, the lineage transgressions and the changes of cell identity at the A/P boundary after ablation of the A or the $P$ compartments are also dependant on JNK up-regulation, which also causes transient slackening of PcG function (Herrera and Morata, 2014). In mammals and zebrafish, wound healing and tissue repair are also related to suppression of PcG genes and reduction of the repressive epigenetic marks (Shaw and Martin, 2009; Stewart et al., 2009). In summary, down-regulation of PcG likely increases cellular plasticity during regeneration and this 
process appears to be facilitated by JNK up regulation.

\section{Differential functions of JNK may explain the differences in the regeneration potential of trunk and appendages}

The JNK pathway plays a critical role in regeneration and is activated after damage in both notum and the wing appendage, thus it would be expected to elicit a response in the two tissues. However, unlike the wing, the notum shows essentially no regenerative response. There is the possibility that the difference in regeneration may be mediated by differential function of JNK in those tissues. In particular, one of the primary roles of JNK, that is, the secretion of proliferative signals, may be lacking in the notum region. Indeed, the ablation of notum regions like the Pnr or Vein domains fails to generate a proliferative response in the surrounding tissue (Martín et al., 2017).

There is evidence that JNK signalling causes distinct effects in the notum and the wing, probably due to the activation of different target genes. Harris et al., (2016), have shown that a specific JNKdependant damage response element is expressed differentially

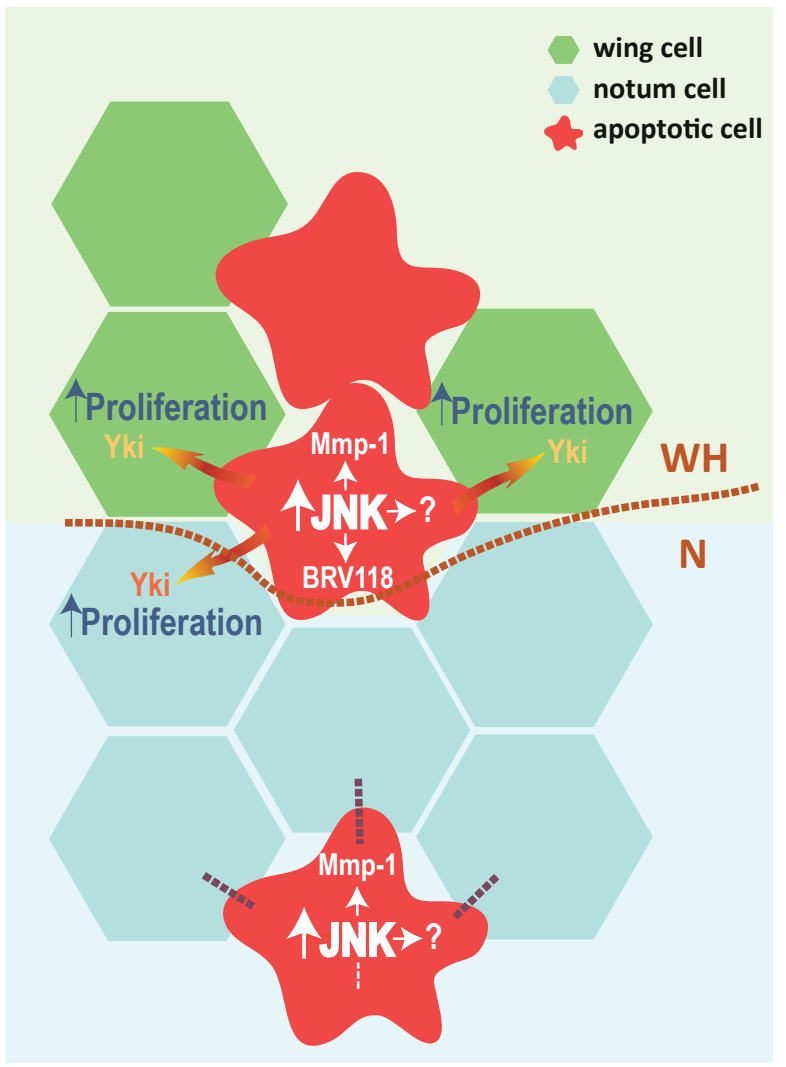

Fig. 3. Model for differences in Jun N-terminal kinase (JNK) signalling caused by apoptotic cells in wing and notum. In the wing territory (green area), JNK signalling is activated in apoptotic cells and it induces the expression of several target genes, like Mmp1 and BRV118 among others. The expression of these and other unknown targets elicits proliferation in surrounding wing and notum living cells, what will provide new cells to repair the damaged tissue. In the notum (blue area) JNK signalling is also activated in apoptotic cells, but it induces the expression of some target genes common to the wing, like Mmp-1, but not of BRV118 and presumably of others necessary for activation of the Yorkie pathway in the surrounding cells. in notum and wing. The expression of this enhancer is induced after tissue damage in wing, but not in notum cells even if JNK is elicited in both regions (Martín et al., 2017). A direct and strong argument for a differential function of JNK in notum and in wing, and by extension in trunk and appendages, comes from the comparison of the consequences of forcing JNK activity in a notum region, the Pnr domain, and in a wing region, the Sal domain. In the latter JNK causes a major overgrowth associated with up regulation of Yorkie (Yki) targets, whereas in the former the Pnr domain maintains its normal size and the expression of Yki targets is not altered (Martín et al., 2017) (Fig. 3).

The duration of JNK activity seems to be important for an efficient regenerative response. In wing disc regeneration, JNK function is sustained even $24 \mathrm{hrs}$ after the ablation is switched off in order to ensure tissue re-growth (Khan et al., 2017). Putative differences in JNK levels between wing and notum cells might also be responsible for their distinct ability to induce the expression of target genes relevant for regeneration. Future work focusing on JNK signalling kinetics in wing and notum cells might be clue to uncover their distinct ability to induce regenerative responses.

\section{Acknowledgements}

We thank all lab members for helpful discussions and comments on the manuscript. This work was supported by the grants BFU2012-32397, BFU2013-50584-EXP and BFU2015-67839-P (MINECO-FEDER) and a grant from the Fundación Ramón Areces.

\section{References}

ALMUEDO-CASTILLO M, CRESPO-YANEZ X, SEEBECK F, BARTSCHERER K SÀLO E, ADELL T (2014). JNK controls the onset of mitosis in planarian stem cells and triggers apoptotic cell death required for regeneration and remodeling. PLoS Genet 10: e1004400.

BEHRENS A, SIBILIA M, DAVID JP, MÖHLE-STEINLEIN U, TRONCHE F, SCHÜTZ G, WAGNER EF (2002). Impaired postnatal hepatocyte proliferation and liver regeneration in mice lacking $\mathrm{c}$-jun in the liver. EMBO J 21: 1782-1790.

BERGANTIÑOS C, COROMINAS M and SERRAS F (2010). Cell death-induced regeneration in wing imaginal discs requires JNK signalling. Development 137: 1169-1179.

BOSCH M, SERRAS F, MARTÍN-BLANCO E and BAGUÑÀ J (2005). JNK signaling pathway required for wound healing in regenerating Drosophila wing imaginal discs. Dev Biol 280: 73-86.

BROCK AR, SETO M, SMITH-BOLTON RK (2017). Cap-n-Collar promotes tissue regeneration by regulating ROS and JNK signalling in the Drosophila melanogaster wing imaginal disc. Genetics 206: 1505-1520.

BRYANT PJ (1975). Pattern formation in the imaginal wing disc of Drosophila melanogaster. fate map, regeneration and duplication. J Exp Zool 193: 49-77.

CHERAS, GHILAL, DOBRETZK, WENGERY, BAUERC, BUZGARIUW, MARTINOU JC, GALLIOT B (2009). Apoptotic cells provide an unexpected source of Wnt3 signalling to drive hydra head regeneration. Dev Cell 17: 279-289.

DÍAZ-BENJUMEAFJ COHEN SM (1993). Interaction between dorsal and ventral cells in the imaginal disc directs wing development in Drosophila. Cell 75: 741-752.

DUNNE JF (1981). Growth dynamics in the regeneration of a fragment of the wing imaginal disc of Drosophila melanogaster. Dev Biol 87: 379-382.

FUCHS Y, STELLER H (2011). Programmed cell death in animal development and disease. Cell 147: 742-758.

GARCÍA-BELLIDO A, RIPOLL P, MORATA G (1973). Developmental compartmentalization of the wing disc of Drosophila. Nat New Biol 245: 251-253.

GURDON JB (1988). Acommunity effect in animal development. Nature336: 772-774.

GURLEY KA, RINK JC, ALVARADO AS (2008). Beta-catenin defines head versus tai identity during planarian regeneration and homeostasis. Science 319: 323-327.

HAYNIE JL, BRYANT PJ (1976). Intercalary regeneration in imaginal wing disk of 


\section{R. Martín and G. Morata}

Drosophila melanogaster. Nature 259: 659-662.

HERRERA SC, MARTÍN R, MORATA G (2013). Tissue homeostasis in the wing disc of Drosophila melanogaster: immediate response to massive damage during development. PLoS Genet. 9: e1003446.

HERRERA SC, MORATA G (2014). Transgressions of compartment boundaries and cell reprogramming during regeneration in Drosophila. Elife 3: e01831.

KAWAKAMI Y RODRIGUEZ ESTEBAN C, RAYA M, KAWAKAMI H, MARTÍ M, DUBOVAI, IZPISÚA-BELMONTEJC (2006). Wnt/beta-catenin signaling regulates vertebrate limb regeneration. Genes Dev 20: 3232-3237.

KHAN SJ, ABIDI SNF, SKINNER A, TIAN Y, SMITH-BOLTON RK (2017). The Drosophila Duox maturation factor is a key component of a positive feedback loop that sustains regeneration signalling. PLoS Genet 13: e1006937.

KING RS, NEWMARK PA (2012). The cell biology of regeneration. J Cell Biol 196: 553-562.

LAWRENCE PA (1992). The making of a fly. Wiley-Blackwell, ISBN 978-0632030484

LAWRENCE PA and MORATA G (1977). The early development of mesothoracic compartments in Drosophila. An analysis of cell lineage and fate mapping and an assessment of methods. Dev Biol 56: 40-51.

LEE N, MAURANGE C, RINGROSE L, PARO R (2005). Suppression of Polycomb group proteins by JNK signalling induces transdetermination in Drosophilaimaginal discs. Nature 438: 234-237.

LENGFELDT, WATANABE H, SIMAKOV O, LINDGENS D, GEE L, LAW L, SCHMIDT HA, ÖZBEK S, BODE H, HOLSTEIN TW (2009). Multiple wnts are involved in hydra organizer formation and regeneration. Dev Biol 330: 186-199.

LIN G, SLACK JM (2008). Requirement for wnt and FGF signaling in Xenopus tadpole tail regeneration. Dev Biol 316: 323-335.

LOVE NR, CHEN Y, ISHIBASHI S, KRITSILIGKOU P, LEA R, KOH Y (2013). Amputation-induced reactive oxygen species are required for successful $X e n o p u s$ tadpole tail regeneration. Nat Cell Biol 15: 222-228.

MARTíN R, PINAL N, MORATA G (2017). Distinct regenerative potential of trunk and appendages of Drosophila mediated by JNK signalling. Development 144: 3946-3956.

MORATA G, HERRERA SC (2016). Cell reprogramming during regeneration in Drosophila: transgression of compartment boundaries. Curr Opin Genet Dev 40:11-16.

MORATA G, LAWRENCE PA (1975). Control of compartment development by the engrailed gene in Drosophila. Nature 255: 614-617.

MORATA G, LAWRENCE PA (1977). Homeotic genes, compartments and cell determination in Drosophila. Nature 265: 211-216.

MORATA G, LAWRENCE PA (1979). Development of the eye-antenna imaginal disc of Drosophila. Dev Biol 70: 355-371.

NIETHAMMER P, GRABHER C, LOOK AT, MITCHISON TJ (2009). A tissue-scale gradient of hydrogen peroxide mediates rapid wound detection in zebrafish. Nature 459: 996-999.

NÖTHIGER R, SCHUBIGER G (1966). Developmental behaviour of fragments of symmetrical and asymmetrical imaginal discs of Drosophila melanogaster(Diptera). J Embr Exp Morphol. 16: 255-268.

PÉREZ-GARIJO A, MARTÍN FA, MORATA G (2004). Caspase inhibition during apoptosis causes abnormal signalling and developmental aberrations in Drosophila. Development 131: 5591-5598.
PÉREZ-GARIJO A, SHLEVKOV E, MORATA G (2009). The role of Dpp and Wg in compensatory proliferation and in the formation of hyperplastic overgrowths caused by apoptotic cells in the Drosophila wing disc. Development 136: 1169-1177.

PETERSEN CP, REDDIEN PW (2008). Smed-catenin-1 is required for anteroposterior blastema polarity in planarian regeneration. Science 319: 327-330.

PIROTTE N, STEVENS AS, FRAGUAS S, PLUSQUIN M, VAN ROTEN A, VAN BELLEGHEM F, PAESEN R, AMELOOT M, CEBRIA F, ARTOIS T, SMEETS K (2015). Reactive oxygen species in planarian regeneration: an upstream necessity for correct patterning and brain formation. Oxid Med Cell Longev 2015: 392476

RYOO HD, GORENC T, STELLER H (2004). Apoptosis can induce compensatory cell proliferation through the JNK and the Wingless signaling pathways. Dev Cell 7: 491-501.

SANTABÁRBARA-RUIZ P, LÓPEZ-SANTILLÁN M, MARTÍNEZ-RODRÍGUEZ I, BINAGUI-CASAS A, PÉREZ L, MILÁN M, COROMINAS M, SERRAS F (2015). ROS-induced JNK and p38 signaling is required for Unpaired Cytokine activation during Drosophila regeneration. PLoS Genet. 11: e1005595.

SHAW T, MARTIN P (2009). Epigenetic reprogramming during wound healing: loss of polycomb-mediated silencing may enable upregulation of repair genes. $E M B O$ Rep 10: 881-886.

SMITH-BOLTON RK, WORLEY MI, KANDA H, HARIHARAN IK (2009). Regenerative growth in Drosophila imaginal discs is regulated by Wingless and Myc. Dev Cell 16: 797-809.

STEWART S, TSUN ZY, IZPISÚA-BELMONTE JC (2009). A histone demethylase is necessary for regeneration in zebrafish. Proc NatlAcad SciUSA 106: 19889-19884.

STOICK-COOPER CL, WEIDINGER G, RIEHLE KJ, HUBBERT C, MAJOR MB, FAUSTO N, MOON RT (2007). Distinct wnt signaling pathways have opposing roles in appendage regeneration. Development 134: 479-489.

SUN G, IRVINE KD (2011). Regulation of Hippo signaling by Jun Kinase signaling during compensatory cell proliferation and regeneration, and in neoplastic tumors. Dev Biol 350: 139-151.

SZABAD J, SIMPSON P, NÖTHIGER R (1979). Regeneration and compartments in Drosophila. J Embryol Exp Morphol 49: 229-241.

TANAKA EM, REDDIEN PW (2011). The cellular basis for animal regeneration. Dev Cell 21: 172-185.

TASAKI J, SHIBATA N, SAKURAI T, AGATA K, UMESONO Y (2011). Role of c-Jun $\mathrm{N}$-terminal kinase activation in blastema formation during planarian regeneration. Dev Growth Differ 53: 389-400.

VERGHESE S, SU TT (2016). Drosophila Wnt and STAT define apoptosis-resistant epithelial cells for tissue regeneration after irradiation. PLOS Biol 14: e1002536.

VRIZ S, REITER S, GALLIOT B (2014). Cell death: a program to regenerate. Curr Top Dev Biol 108: 121-151.

WORLEY MI, SETIAWAN L, HARIHARAN IK (2012). Regeneration and transdetermination in Drosophila imaginal discs. Ann Rev Genet 46: 289-310.

YOKOYAMA H, OGINO H, STOICK-COOPER CL, GRAINGER RM, MOON RT (2007). Wnt/Beta-catenin signaling has an essential role in the initiation of limb regeneration. Dev Biol 306: 170-178.

ZECCA M, STRUHL G. (2002). Subdivision of the Drosophila wing imaginal disc by EGFR-mediated signaling. Development 129: 1357-1368. 


\section{Further Related Reading, published previously in the Int. J. Dev. Biol.}

Cell competition, apoptosis and tumour development

Ginés Morata and Luna Ballesteros-Arias

Int. J. Dev. Biol. (2015) 59: 79-86

https://doi.org/10.1387/ijdb.150081gm

Apoptosis in Drosophila: compensatory proliferation and undead cells

Francisco A. Martín, Ainhoa Peréz-Garijo and Ginés Morata

Int. J. Dev. Biol. (2009) 53: 1341-1347

https://doi.org/10.1387/ijdb.072447fm

PVF1/PVR signaling and apoptosis promotes the rotation and dorsal closure of the Drosophila male terminalia Ana Macías, Nuria M. Romero, Francisco Martín, Leonardo Suárez, Alberto L. Rosa and Ginés Morata

Int. J. Dev. Biol. (2004) 48: 1087-1094

http://www.intjdevbiol.com/web/paper/041859am

Regulation and activity of JNK signaling in the wing disc peripodial membrane during adult morphogenesis in Drosophila Chaturvedula Tripura, Nulu-Prafulla Chandrika,Vutukuru-Nagalakshmi Susmitha, Stéphane Noselli and LS Shashidhara

Int. J. Dev. Biol. (2011) 55: 583-590

https://doi.org/10.1387/ijdb.103275ct

Origin and proliferation of blastema cells during regeneration of Drosophila wing imaginal discs

Manel Bosch, Jaume Baguñà and Florenci Serras

Int. J. Dev. Biol. (2008) 52: 1043-1050

https://doi.org/10.1387/ijdb.082608mb

A screen for genes expressed in Drosophila imaginal discs Offer Gerlitz, Denise Nellen, Michael Ottiger and Konrad Basler Int. J. Dev. Biol. (2002) 46: 173-176

http://www.intjdevbiol.com/web/paper/11902680

Larval and imaginal pathways in early development of Drosophila R Harbecke, M Meise, A Holz, R Klapper, E Naffin, V Nordhoff and W Janning Int. J. Dev. Biol. (1996) 40: 197-204

http://www.intjdevbiol.com/web/paper/8735929

5 yr ISI Impact Factor $(2016)=2.421$
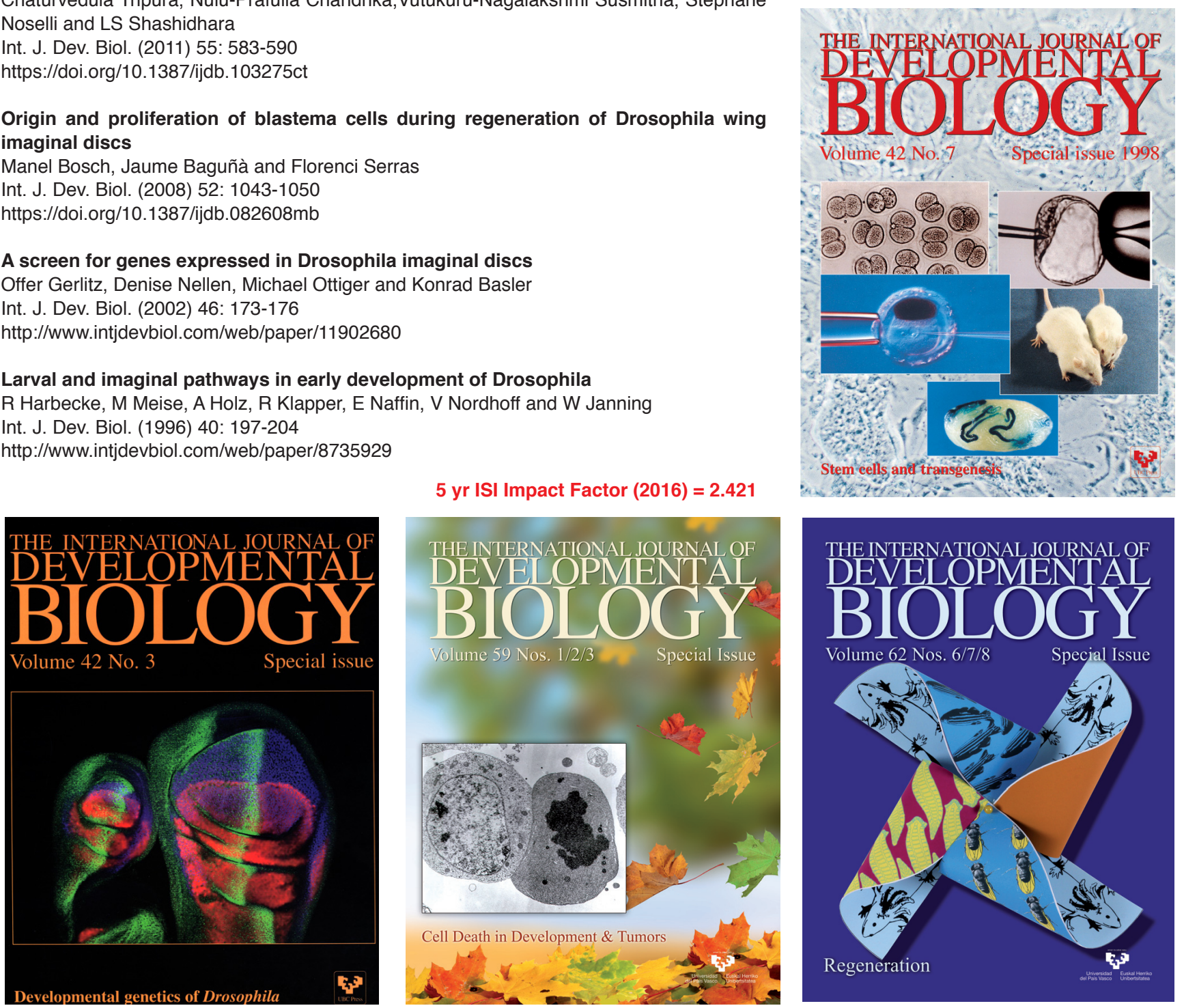